\title{
Stimulus generalization of a CER in young and adult rats
}

\author{
TERRY P. MCGAUGHEY and WILLIAM R. THOMPSON \\ Queen's University, Kingston, Ontario, Canada
}

\begin{abstract}
Groups of rats of 20-22 and 78-80 days of age were given CER training to a tone. Two other groups at each age were either given tone-alone presentations or randomized presentations of tone and shock. At testing, some subjects were presented with the training tone and others with one of two generalization tones. A heart-rate ratio indicated little evidence of acquisition in adults and flat generalization curves. In contrast, young subjects showed clear CER learning and a steep generalization curve.
\end{abstract}

The present study compares the capacities of young and adult rats to generalize from an auditory aversive conditioned stimulus to other stimuli of the same modality. Recent studies dealing with this problem are few in number but suggest that generalization gradients are steeper in young than in adults (Frieman, Rohrbaugh \& Riccio, 1969; Frieman, Warner, \& Riccio, 1970; Rohrbaugh \& Riccio, 1968). This important result deserves to be further evaluated, in particular, by the use of more simple and direct indices of conditioning than those used in the studies above. To this end, we have chosen heart-rate change as an index of classical conditioning. Although it is a measure with its own set of complications and is by no means unrelated to ongoing somatic activity (Vanderwolf \& Vanderwolf, 1970), it does, at least, reduce instrumental response components to a minimum. In this latter respect, it, therefore, seems preferable to the more complex measures often used.

\section{METHOD}

\section{Subjects}

The subjects were 36 male and 36 female Sprague-Dawley albino rats born and reared in the Queen's Laboratory. After weaning, the subjects were divided by sex and transferred to group living cages with four subjects per cage and maintained on an ad-lib diet of Purina lab chow and water. Thirty-six were assigned randomly to the 20-22 day-old groups and 36 to the 78-80 day-old group. At each level, 12 were assigned randomly to each of the three treatment groups.

\section{Apparatus}

Heart rate was recorded from stainless steel wire electrodes ( $.30 \mathrm{ga}$ for adults and $.28 \mathrm{ga}$ for young) leading to an Onyx telemetry transmitter housed on the top of the test box. The signal was received by an Onyx telemetry receiver (Model RSBC-35) and recorded on a Grass polygraph (Model 5A). In the case of adult subjects, this basic unit was slightly modified to include a Krohn-Hite Model 3750 filter and recording on a Beckman Type R.P. dynograph recorder.

Apparatus for CER training and testing consisted of a

This work was supported by grants-in-aid from the National Research Council of Canada (AP-180), the Queen's University Research Committee and by a Canada Council Senior Fellowship to the second author. plywood box $24.77 \times 23.50 \times 28.58 \mathrm{~cm}$ with Plexiglas roof. On one of the sides of the box was mounted a $3-\mathrm{ohm}, 10-\mathrm{cm}$ speaker connected to a Hewlitt-Packard Model 201C audio-oscillator. Volume for the three tones used in the study was maintained $80 \mathrm{~dB}$ as measured by a General Radio Company sound level meter, Model 1551c. Scrambled .6-mA shock was delivered through the grid floor of the box by a Grason-Stadler Model e6070B shock generator. Tone and shock presentations were carried out by means of automatic programming equipment.

\section{Surgery}

Implantation of subcutaneous electrodes was performed under light ether anesthesia. A hypodermic needle, threaded with the electrode wire, was passed through a fold of the subject's skin, and then twisted firmly about the fold. The wound was sealed by a few drops of collodium. One electrode was placed just anterior to the pelvis, the other just posterior to the scapula.

\section{Procedure}

Between 48 and $60 \mathrm{~h}$ following surgery, each subject was placed in the test box with electrodes connected for a 10-min habituation period. During this phase, HR was recorded for the first and final $45 \mathrm{sec}$. Following habituation, electrodes were disconnected and CER acquisition commenced. Subjects were randomly assigned to three treatment groups at each age level: (a) the paired group received $105-\mathrm{sec}$ tones of $1200 \mathrm{~Hz}$ delivered on a VI 1-min schedule $(40-, 60-$, or $80-\mathrm{sec}$ intervals) with a 1 -sec .6-mA shock delivered at tone off set; (b) The TRC group ("truly random control") received the same number of tones and shocks but with the schedules of each randomized in respect to intervals; (c) the tone-alone group received 10 trials of tone alone on the 1-min VI schedule.

One minute following the acquisition trials, electrodes were reconnected and test trials commenced. The subjects were randomly allocated to three further subgroups, each being tested with either the $1200-\mathrm{Hz}$ training tone or a $1000-\mathrm{Hz}$ generalization or a $1400-\mathrm{Hz}$ generalization tone. There were five test-tone presentations delivered on the same 1-min VI schedule.

\section{Data Recording and Analysis}

Heart rate was scored manually by the experimenter in terms of beats-per-minute (BPM) and converted into ratio form to yield three types of score as follows:

\section{(a) BPM 5-sec pretone - BPM during tone} BPM 5-sec pretone

(b) BPM 5-sec pretone - BPM 5-sec post tone BPM 5-sec pretone 
(c) BPM during tone - BPM 5-sec posttone BPM during tone

These measures indicated, respectively, HR changes at stimulus onset; HR changes pre- to poststimulus; and HR changes relating to stimulus offset. They were used in line with data previously obtained by Rundel, Niemi, and Thompson (1971) showing differential age effects in sensory preconditioning according to whether onset or offset measures were used. For each measure, a positive score indicated a HR deceleration, a negative score, HR acceleration.

HR ratio scores were averaged over the five signal presentations. Scores were analyzed by means of the approximate method of unweighted means (Winer, 1962) with ages, treatments and tones as the variables. Planned orthogonal comparisons were also carried out according to the procedure described by Edwards (1968).

\section{RESULTS}

For the first measure, a significant effect was obtained for the treatment-tones interaction $(F=5.741$, $\mathrm{p}<.001$ ) indicating a more differentiated response of all subjects in the paired group to the training as compared to the two generlization tones. However, the more critical result is contained in a significant second-order interaction between all three variables $(F=3.35$, $p<.05)$. These data are shown graphically in Figure 1 . Generally speaking, they appear to indicate a rather large conditioning effect and much less generalization in young as compared with adult animals. In fact, orthogonal comparisons indicate conditioning (paired vs. TRC groups) only in young subjects $(F=4.88, p<.05)$. Further, a comparison of the quadratic components of HRR gradients indicated that the gradients shown by the young are significantly steeper than the relatively flat gradients shown by the adults $(\mathrm{F}=8.78, \mathrm{p}<.005)$. The same comparison for the tone-alone group yielded no significant difference between young and adult gradients $(\mathrm{F}=1.00)$.

In the case of the second measure, only the tones variable was found to be significant $(F=4.06, p<.025)$, indicating a strong deceleratory response to the training tone, but acceleratory responses to the generalization tones.

For the third measure, young were found to be more reactive than adults to all tones $(\mathrm{F}=5.28, \mathrm{p}<.05)$, both age groups showing predominantly acceleratory response. These results for offset effects contrast with the mainly deceleratory responses shown by the subjects to tone onset as reflected in the first measure.

\section{DISCUSSION}

In respect to learning and generalization, only the onset measure yielded results of interest. In the first place, it seems clear that if conditioning did occur in the adults, it showed rapid extinction; whereas, in young subjects, conditioning was shown to have occurred and did not extinguish over the five test trials. This result is in agreement with the data of Snedden, Spevak, and Thompson (1971) and also of Frieman, Frieman, Wright,

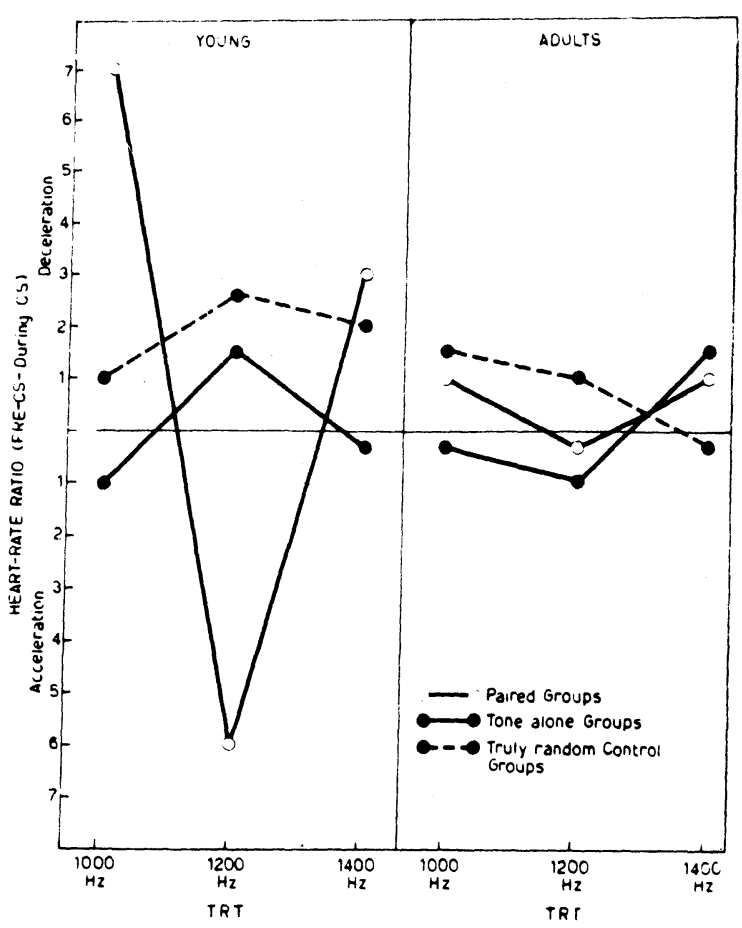

Figure 1. Generalization of a CER from a training tone (TRT) in young and adult rats: heart-rate ratios.

and Hegberg (1971), though contrary to the results of Campbell and Campbell (1962) and of Kirby (1963). As Frieman et al. indicate (p. 428), this discrepancy is most likely due to the relatively prolonged acquisition phase in these latter studies and the brief one in their own (and ours). Further work on this important point is needed.

The second major result obtained using the first heart-rate score was that young animals show much steeper generalization gradients than adults. This finding is again in agreement with the results of Frieman et al. $(1969,1970)$ and of Rohrbaugh and Riccio (1968). Frieman et al. (1971) suggested that this phenomenon might be due to more rapid extinction of aversive conditioning in young animals. However, such a hypothesis does not seem very compelling. We might well argue, on the contrary, that young animals extinguish slowly for the training stimulus but rapidly for generalization stimuli, thus evincing a steep gradient at least at some point during the extinction phase. Consequently, the relation between extinction rate and generalization in young and adult animals remains to be further elucidated.

Ambiguous as our data may be theoretically, nevertheless they are of importance in that they are consonant with the finding of some other investigators in the area of animal development. Such agreement in this complex field is reassuring and should encourage more elaborate exploration of the problem of age differences in generalization.

\section{REFERENCES}

Campbell, B. A., \& Campbell, E. H. Retention and extinction of learned fear in infant and adult rats. Journal of Comparative and Physiological Psychology, 1962, 55, $1-8$.

Edwards, A. L. Statistical design in psychological research. 3rd Ed. New York: Holt, Rinehart, 1968.

Frieman, J. P., Frieman, J., Wright, W., \& Hegberg W. Developmental trends in the acquisition and extinction of conditioned suppression in rats. Developmental Psychology, $1971,4,425-428$. 
Frieman, J. P., Rohrbaugh, M. \& Riccio, D. C. Age differences in the control of acquired fear by tone. Canadian Journal of Psychology, 1969, 23, 237-244.

Frieman, J. P., Warner, J. \& Riccio, D. C. Age differences in conditioning and generalization of fear in young and adult rats. Developmental Psychology, 1970, 3, 119-123.

Kirby, R. H. Acquisition, extinction and retention of an avoidance response as a function of age. Journal of Comparative and Physiological Psychology, 1963, 56, 158-162.

Rohrbaugh, M. \& Riccio, D. C. Stimulus generalization of learned fear in infant and adult rats. Journal of Comparative and Physiological Psychology, 1968, 66, 530-533.
Rundle, G. P., Niemi, R. \& Thompson, W. R. Sensory preconditioning effects in young and adult rats. Canadian Journal of Psychology, 1971, 25, 323-325.

Snedden, D. S., Spevak, A. A., \& Thompson, W. R. Conditioned and unconditioned suppression as a function of age in rats. Canadian Journal of Psychology, 1971, 25, 313-322.

Vanderwolf, C. H., \& Vanderwolf, M. L. Relations of heart rate to motor activity and arousal in the rat. Canadian Journal of Psychology, 1970, 24, 434-442.

Winer, B. J. Statistical Principles in experimental design. New York: McGraw-Hill.

(Received for publication Novem ber 25, 1974.)

\title{
Temporal contiguity: Is it a sufficient condition for reinforcement?
}

\author{
ROBERT G. HARRISON \\ Anclote Manor, Tarpon Springs, Florida 33589 \\ and \\ ROBERT W. SCHAEFFER \\ Auburn University, Auburn, Alabama 36830.
}

\begin{abstract}
Utilizing an experimental paradigm described by Premack, an attempt was made to determine whether temporal contiguity between differentially probable responses was a sufficient condition for reinforcement. Using six rats as subjects, and running in an activity wheel and drinking a sucrose solution as responses, it was determined that mere temporal contiguity of a high probability response subsequent to a low probability responses was not a sufficient condition for reinforcement. These data were discussed with respect to important procedural questions regarding appropriate response baseline referents from which reinforced increments in responding are to be inferred.
\end{abstract}

Herrnstein (1966) and Sidman (1960) have maintained that temporal contiguity alone is a sufficient condition for reinforcement to occur and have cited Skinner's (1948) classic paper on superstitious behavior in the pigeon as conclusive evidence for this allegation. Premack (1965) has observed, however, that the reinforcement relationship typically includes, in addition to the readily recognized factor of temporal contiguity, three additional, but less commonly recognized, experimenter-imposed conditions: (1) an instrumental response requirement, (2) a reduction in the amount or duration of reinforced responding, and (3) a circumscribing of the response distribution permitted for reinforced responding. The minimal condition required to determine the role of temporal contiguity in the reinforcement relation, according to Premack, would involve the mere temporal pairing of $\mathrm{L}$, a low probability response, and $\mathrm{H}$, a high probability response, without

The research for this paper was supported by Public Health Research Grants $\mathrm{MH}-08775$ and $\mathrm{MH}-12025$ from the National Institute of Mental Health, R. W. Schaeffer, principal investigator. any of the other three experimenter-imposed conditions present. Such a minimal case would occur when both $\mathrm{L}$ and $\mathrm{H}$ are freely and concurrently available, given that $\mathrm{H}$ follows $\mathrm{L}$ in close temporal proximity on one or more occasions. To test this hypothesis, Premack (1965) arranged a behavioral condition in which only running (L) or licking $(\mathrm{H})$ was available (i.e., a single baseline) to determine the independent probability of each response, then made $\mathrm{L}$ and $\mathrm{H}$ freely and concurrently available (i.e., a paired baseline), and finally tested the probabibility of running (L) alone in an "extinction" phase. Relative to total running in the single baseline, total running in the paired baseline was less; during "extinction," the probability of running did not differ significantly from the probability of running in the initial single baseline condition. Premack concluded that (a) no reinforcement had occurred in the paired baseline conditions in spite of frequent temporal contacts between the two responses and (b) temporal contiguity could not, therefore, be labeled a sufficient condition for reinforcement to occur.

Although Premack (1965) utilized the single baseline 